\title{
FREQUÊNCIA DE NEOPLASIAS CUTÂNEAS EM CÃES ATENDIDOS NO HOSPITAL VETERINÁRIO DA UNIVERSIDADE FEDERAL DE UBERLÂNDIA DURANTE OS ANOS 2000 A 2010
}

\author{
FREQUENCY OF SKIN CANCER IN DOGS TREATED AT THE FEDERAL \\ UNIVERSITY OF UBERLÂNDIA VETERINARY HOSPITAL FROM 2000 TO 2010
}

\author{
Carla Cristiane FERNANDES ${ }^{1}$; Alessandra Aparecida MEDEIROS ${ }^{1}$; \\ Geórgia Modé MAGALHÃES ${ }^{2}$; Matias Pablo Juan SZABÓ ${ }^{1}$; Rodrigo Pereira de QUEIROZ ${ }^{\mathbf{1}}$; \\ Marcus Vinícius Alves da SILVA ${ }^{1}$; Nicolle Pereira SOARES ${ }^{1}$ \\ 1. Universidade Federal de Uberlândia, Faculdade de Medicina Veterinária, Uberlândia, MG, Brasil. alessandra@famev.ufu.br; \\ 2.Universidade de Franca, Programa de Pós-graduação em Medicina Veterinária de Pequenos Animais, Franca, SP, Brasil.
}

RESUMO: Foram analisados os arquivos do laboratório de Patologia Animal do Hospital Veterinário da UFU de janeiro de 2000 a dezembro de 2010, selecionando protocolos referentes a biopsias cutâneas de cães coletando-se as seguintes informações: diagnóstico morfológico, localização anatômica, idade, sexo e raça dos cães, com o objetivo de realizar um estudo epidemiológico. Foram diagnosticados 549 tumores cutâneos em 543 cães, sendo que 281 cães eram machos e 247 fêmeas. Cães adultos e idosos foram os mais acometidos, assim como os cães sem raça definida, Poodle, Boxer, Pit Bull e Dashchund. Os tumores malignos prevaleceram com 65,39\% dos casos, sendo os de origem epitelial os mais frequentes. O carcinoma de células escamosas foi a neoplasia predominante, seguido pelo mastocitoma e histiocitoma. Com relação á localização anatômica prevaleceu as regiões do abdômen (19,49\%), cabeça (16,40\%) e membros $(15,30 \%)$. Não houve diferença na probabilidade de apresentar tumor cutâneo com relação ao sexo, porém considerando-se os tipos de tumores há maior probabilidade da população canina apresentar carcinoma de células escamosas e mastocitomas em detrimento dos outros tipos de tumores cutâneos.

PALAVRAS-CHAVE: Mastocitoma. Pele. Canino. Carcinoma de células escamosas. Tumores.

\section{INTRODUÇÃO}

A dermatologia de pequenos animais é um campo em expansão na medicina veterinária e os distúrbios de pele representam aproximadamente 30 a $40 \%$ dos casos vivenciados na clínica de animais de companhia (WILLEMSE, 1998) e dos cães que apresentam algum tipo de tumor, cerca de $30 \%$ são neoplasias de pele (GOORMAN; DOBSON, 1995; WITHROW; VAIL, 2001).

$\mathrm{O}$ grande número de tumores cutâneos em cães se deve ao fato que a pele é o maior órgão do corpo e representa a barreira física entre o ambiente e organismo (JONES et al., 2000) e possui exposição direta a fatores oncogênicos propiciando as formações neoplásicas (MEDLEAU; HNILICA, 2009). Além disso, a pele possui inúmeras células e há um alto índice de renovação celular sendo susceptível a mutações (MURPHY, 2006). A prevalência das neoplasias entre os animais de estimação também tem aumentado consideravelmente em decorrência de uma sobrevida mais longa destes animais (MORRISON, 1998).

O objetivo foi realizar estudo epidemiológico das neoplasias cutâneas de cães, diagnosticadas no Laboratório de Patologia Animal do Hospital Veterinário da Universidade Federal de Uberlândia (UFU), descrevendo os tumores encontrados e correlacionando-os com a raça, idade, sexo e localização anatômica e ainda calcular o risco em relação ao sexo e aos tumores mais frequentes.

\section{MATERIAL E MÉTODOS}

Para o estudo foram analisados os arquivos do Laboratório de Patologia Animal do Hospital Veterinário da UFU de janeiro de 2000 a dezembro de 2010, selecionando protocolos referentes a biopsias cutâneas de cães de Uberlândia e região. As seguintes informações foram coletadas: diagnóstico morfológico, localização anatômica, idade, sexo e raça dos cães. Todos os fragmentos de pele haviam sido fixados em formol a $10 \%$, processados histologicamente e corados pela Hematoxilina e Eosina (HE) para determinação do diagnóstico morfológico.

Dentre os diagnósticos morfológicos selecionados foram considerados apenas aqueles de origem neoplásica. Os tumores foram classificados de acordo com Goldschmidt e Hendrick (2002) e os sítios anatômicos considerados foram: cabeça, pescoço, membro, tórax, abdômen, períneo, cauda e escroto. Quando o cão apresentava mais de uma 
lesão cutânea neoplásica de tipos histológicos diferentes eram incluídos separadamente no levantamento, mas quando eram do mesmo tipo histológico este era classificado como tumor multifocal.

Quanto à faixa etária os cães foram agrupados como: filhotes (até um ano de idade), adultos (um a oito anos) e idosos (mais de oito anos).

Os resultados foram analisados na forma de estatística descritiva e calculou-se o risco de ocorrência de neoplasias cutâneas em relação ao sexo e aos tipos de neoplasias mais frequentes utilizando o teste Qui Quadrado (Odds Ratio).

\section{RESULTADOS}

Foram diagnosticadas 549 neoplasias cutâneas em 543 cães. Destes animais, 281 eram machos $(51,75 \%), 247$ eram fêmeas $(45,49 \%)$ e 15 casos $(2,76 \%)$ não havia informação sobre o sexo dos animais (Figura 1). Observou-se Odds Ratio (OR) 0,86 de $(0,72<\mathrm{OR}<1,02)$ com intervalo de confiança $95 \%$ e um $\mathrm{p}=0,11$ não havendo diferença significativa no risco de apresentar tumor quando comparados os sexos.

\section{SEXO}

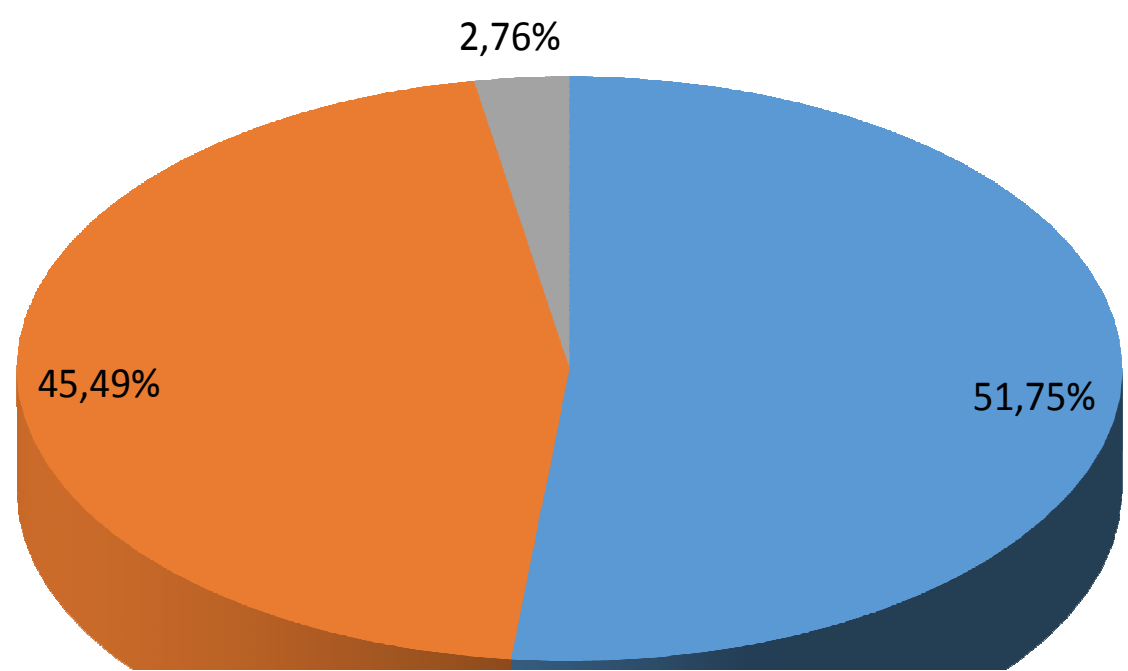

Figura 1. Percentagem de cães com neoplasia cutânea atendidos no hospital Veterinário da UFU, segundo o sexo, entre janeiro de 2000 a dezembro de 2010.

Entre esses cães, 14 eram filhotes $(2,58 \%)$, 226 adultos (41,62\%), 265 idosos $(48,80 \%)$ (Figura 2) e os adultos e idosos foram os grupos que apresentaram neoplasias cutâneas com maior frequência (Tabela 1).

O carcinoma de células escamosas e papiloma foram as neoplasias mais frequentes em filhotes, assim como carcinoma de células escamosas mastocitoma e histiocitoma foram as neoplasias mais frequentes em adultos e idosos.

Cães de 30 raças diferentes foram diagnosticados com neoplasias cutâneas, porém cães sem raça definida foram os mais frequentes $(25,41 \%)$. E as quatro raças mais acometidas foram Poodle 9,76\% (n=53); Boxer 9,39\% $(n=51)$; American Pit Bull Terrier (Pit Bull) 6,99\% (n=38) e Dashchund 5,70\% ( $\mathrm{n}=31$ ) (Figura 3).
Do total de 549 neoplasias cutâneas 65,39\% $(n=359)$ eram malignas e $34,61 \%(n=190)$ benignas. Sendo que $39,89 \% \quad(\mathrm{n}=219)$ foram de origem epitelial; 28,42\% $(n=156)$ mesenquimais, $25,86 \%$ $(n=142)$ de células redondas e 5,83\% $\quad(n=32)$ melanocíticos.

Os tumores mais frequentes foram carcinoma de células escamosas 15,48\% $(n=85)$; mastocitoma $15,30 \% \quad(n=84)$; histiocitoma $7,65 \%$ $(\mathrm{n}=42)$; carcinoma de células basais $6,73 \%(\mathrm{n}=37)$; hemangioma 5,64\% $\quad(n=31)$; melanoma $5,28 \%$ $(n=29) ; \quad$ hemangiossarcoma $4,91 \% \quad(n=27)$; lipossarcoma 4,91\% $(n=27)$; lipoma 3,64\% $(n=20)$ e fibroma 3,64\% $(n=20)$ (Tabela 2). 


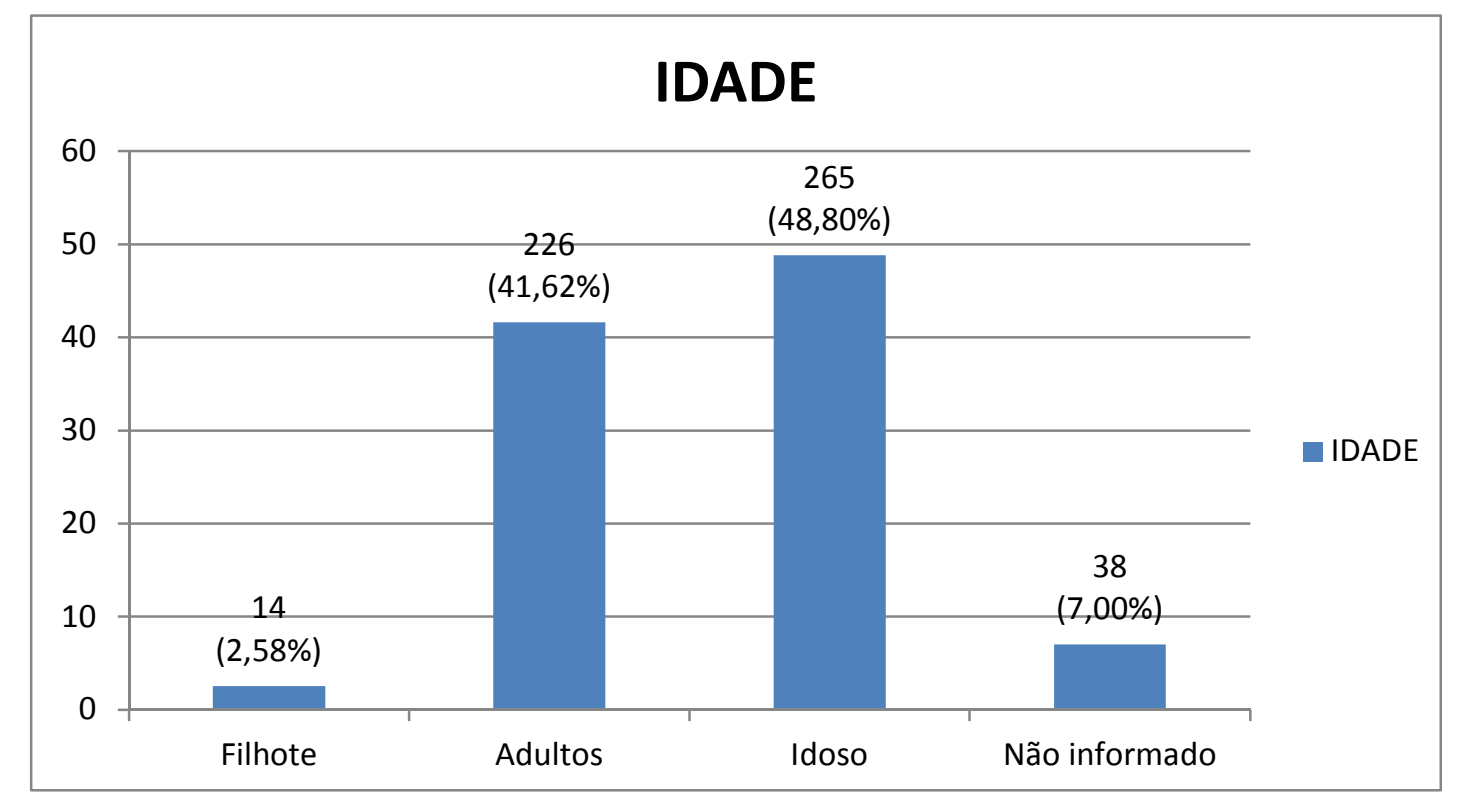

Figura 2. Número e percentual de cães com neoplasias cutâneas atendidos no Hospital Veterinário da UFU, segundo a faixa etária, entre janeiro de 2000 a dezembro de 2010.

Tabela 1. Frequência de neoplasias cutâneas em 505 cães atendidos no Hospital Veterinário da Universidade Federal de Uberlândia, segundo o grupo etário, entre janeiro de 2000 a dezembro 2010.

\begin{tabular}{lccr}
\hline \multicolumn{1}{c}{ Neoplasias } & Filhote (\%) & Adulto (\%) & Idoso (\%) \\
\hline Carcinoma células escamosas & $03(0,59 \%)$ & $31(6,13 \%)$ & $50(9,90 \%)$ \\
Mastocitoma & $02(0,39 \%)$ & $33(6,53 \%)$ & $44(8,71 \%)$ \\
Histiocitoma & $02(0,39 \%)$ & $20(3,96 \%)$ & $14(2,77 \%)$ \\
Carcinoma de células basais & 0 & $15(2,97 \%)$ & $12(2,37 \%)$ \\
Hemangioma & 0 & $20(3,96 \%)$ & $11(2,17 \%)$ \\
Melanoma & 0 & $13(2,57 \%)$ & $15(2,97 \%)$ \\
Hemangiossarcoma & 0 & $15(2,97 \%)$ & $08(1,58 \%)$ \\
Lipossarcoma & 0 & $05(0,99 \%)$ & $17(3,36 \%)$ \\
Lipoma & $02(0,39 \%)$ & $08(1,58 \%)$ & $10(1,98 \%)$ \\
Fibroma & $02(0,39 \%)$ & $07(1,38 \%)$ & $11(2,17 \%)$ \\
Fibrossarcoma & 0 & $07(1,38 \%)$ & $12(2,37 \%)$ \\
Adenoma de glândula perianal & 0 & $08(1,58 \%)$ & $07(1,38 \%)$ \\
Adenocarcinoma de glândula sebácea & 0 & $04(0,79 \%)$ & $08(1,58 \%)$ \\
Adenoma de glândula sebácea & 0 & $05(0,99 \%)$ & $08(1,58 \%)$ \\
TVT & 0 & $03(0,59 \%)$ & $09(1,78 \%)$ \\
Adenocarcinoma de glândula perianal & 0 & $05(0,99 \%)$ & $08(1,58 \%)$ \\
Papiloma & $03(0,59 \%)$ & $07(1,38 \%)$ & 0 \\
Tricoepitelioma & 0 & $02(0,39 \%)$ & $04(0,79 \%)$ \\
Adenocarcinoma glândula sudorípara & 0 & $02(0,39 \%)$ & $03(0,59 \%)$ \\
Adenoma glândula sudorípara & 0 & $04(0,79 \%)$ & $01(0,19 \%)$ \\
Mixoma & 0 & $02(0,39 \%)$ & $03(0,59 \%)$ \\
Hemangiopericitoma & 0 & $02(0,39 \%)$ & $02(0,39 \%)$ \\
\hline
\end{tabular}




\begin{tabular}{llcc}
\hline Linfoma & 0 & $03(0,59 \%)$ & 0 \\
Melanoma amelânico & 0 & 0 & $02(0,39 \%)$ \\
Mixossarcoma & 0 & 0 & $03(0,59 \%)$ \\
Epitelioma sebáceo & 0 & $01(0,19 \%)$ & 0 \\
Adenoma de glândula de meibômio & 0 & $01(0,19 \%)$ & $01(0,19 \%)$ \\
Tumor basoescamoso & 0 & $02(0,39 \%)$ & 0 \\
Condroma & 0 & 0 & $01(0,19 \%)$ \\
Adenoma glândula ceruminolítica & 0 & $01(0,19 \%)$ & 0 \\
Plasmocitoma & 0 & 0 & $01(0,19 \%)$ \\
\hline \multicolumn{1}{c}{ TOTAL } & $14(2,77 \%)$ & $226(44,75 \%)$ & $265(52,48 \%)$ \\
\hline
\end{tabular}

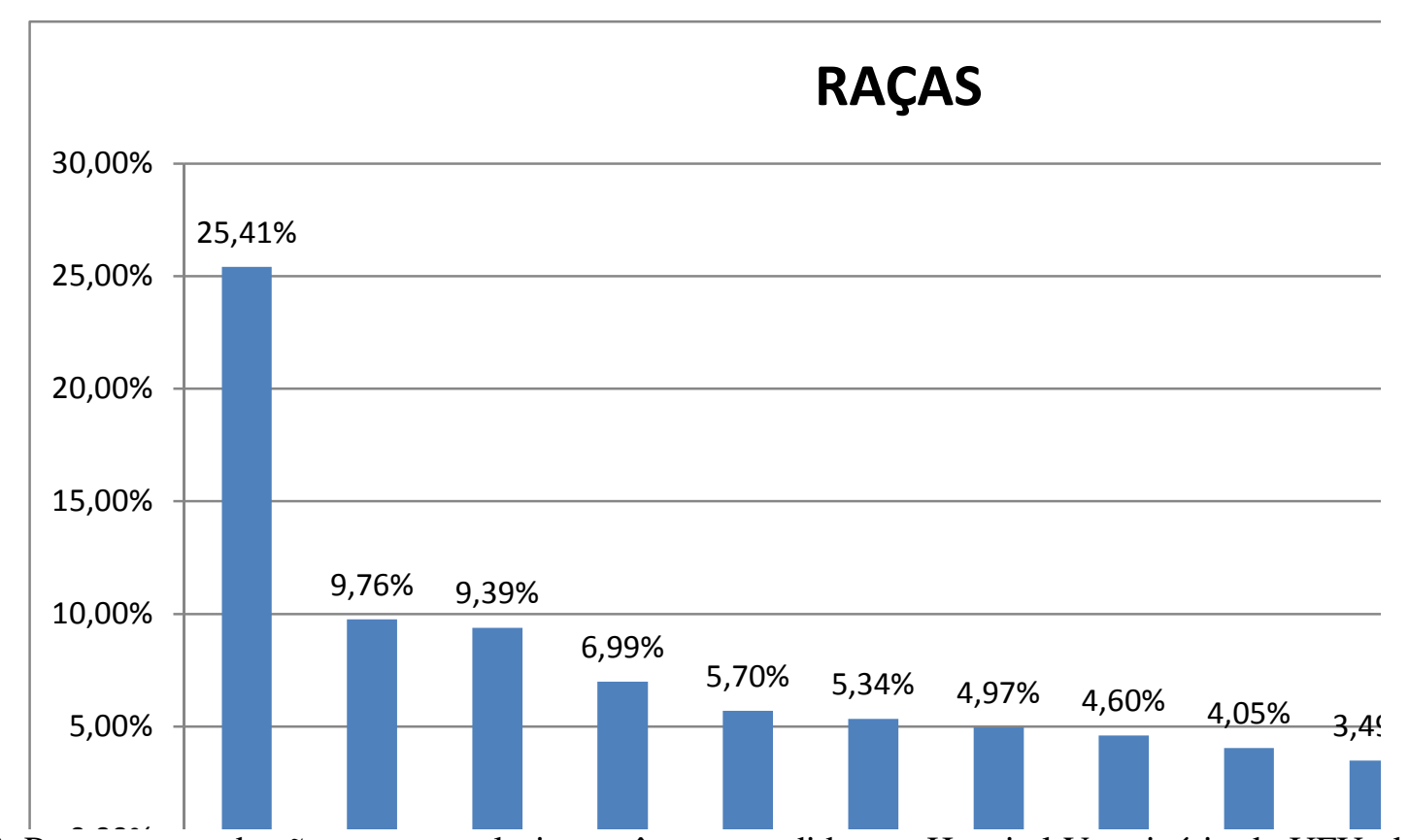

Figura 3. Percentagem de cães com neoplasias cutâneas atendidos no Hospital Veterinário da UFU, de acordo coma a raça, entre janeiro de 2000 a dezembro de 2010.

Tabela 2. Frequência das neoplasias cutâneas diagnosticados em cães atendidos no Hospital veterinário da Universidade Federal de Uberlândia, entre janeiro de 2000 a dezembro de 2010.

\begin{tabular}{lcc}
\hline Neoplasias & $\begin{array}{c}\text { Número de cães } \\
\text { portadores }\end{array}$ & Percentagem \\
\hline Carcinoma de células escamosas & 85 & $15,48 \%$ \\
Mastocitoma & 84 & $15,30 \%$ \\
Histiocitoma & 42 & $7,65 \%$ \\
Carcinoma células basais & 37 & $6,74 \%$ \\
Hemangioma & 31 & $5,64 \%$ \\
Melanoma & 29 & $5,28 \%$ \\
Hemangiossarcoma & 27 & $4,92 \%$ \\
Lipossarcoma & 27 & $4,92 \%$ \\
Lipoma & 20 & $3,64 \%$ \\
Fibroma & 20 & $3,64 \%$ \\
Fibrossarcoma & 20 & $3,64 \%$ \\
Adenocarcinoma de glândula perianal & 17 & $3,09 \%$ \\
Adenoma glândula perianal & 15 & $2,73 \%$ \\
Adenocarcinoma de glândula sebácea & 13 & $2,36 \%$ \\
\hline
\end{tabular}




\begin{tabular}{lcc}
\hline Adenoma de glândula sebácea & 13 & $2,36 \%$ \\
TVT & 12 & $2,18 \%$ \\
Papiloma & 10 & $1,82 \%$ \\
Tricoepitelioma & 8 & $1,45 \%$ \\
Adenocarcinoma glândula sudorípara & 5 & $0,91 \%$ \\
Adenoma glândula sudorípara & 5 & $0,91 \%$ \\
Mixoma & 5 & $0,91 \%$ \\
Hemangiopericitoma & 4 & $0,73 \%$ \\
Linfoma & 3 & $0,54 \%$ \\
Melanoma amelânico & 3 & $0,54 \%$ \\
Mixossarcoma & 3 & $0,54 \%$ \\
Epitelioma sebáceo & 3 & $0,54 \%$ \\
Adenoma da glândula meibomio & 2 & $0,36 \%$ \\
Tumor basoescamoso & 2 & $0,36 \%$ \\
Condroma & 1 & $0,18 \%$ \\
Adenoma de glândula apócrina & 1 & $0,18 \%$ \\
Adenoma de glândula ceruminolítica & 1 & $0,18 \%$ \\
Plasmocitoma & 1 & $0,18 \%$ \\
\hline TOTAL & 549 & $100 \%$ \\
\hline
\end{tabular}

A localização anatômica mais frequente foi abdômen 19,49\% ( $\mathrm{n}=107)$; cabeça 16,40\% ( $\mathrm{n}=90)$; membros $15,30 \%(n=84)$; perianal $9,65 \% \quad(n=53)$; escroto 7,29\% $(\mathrm{n}=40)$; tórax $6,19 \%(\mathrm{n}=34)$; tumores multifocais $3,83 \%(n=21)$; pescoço $2,73 \%(n=15)$ e cauda $1,45 \% \quad(\mathrm{n}=8)$. Tumores em outras localizações que não as consideradas neste estudo foram identificadas em $17,67 \%$ dos casos $(n=97)$. As neoplasias com maior frequência encontradas nessas regiões estão descritas na tabela 3 .

Tabela 3. Frequência de neoplasias cutâneas classificada segundo sua localização anatômica em cães atendidos no Hospital veterinário da Universidade Federal de Uberlândia entre janeiro de 2000 a dezembro de 2010.

\begin{tabular}{lcc}
\hline Localização & $\begin{array}{c}\text { Número de cães } \\
\text { portadores }\end{array}$ & Percentagem \\
\hline Abdômen & 107 & $19,49 \%$ \\
Cabeça & 90 & $16,40 \%$ \\
Membros & 84 & $15,30 \%$ \\
Perianal & 53 & $9,65 \%$ \\
Escroto & 40 & $7,29 \%$ \\
Tórax & 34 & $6,19 \%$ \\
Tumores Multifocais & 21 & $3,83 \%$ \\
Pescoço & 15 & $2,73 \%$ \\
Cauda & 8 & $1,45 \%$ \\
Outras localizações & 97 & $17,67 \%$ \\
\hline TOTAL & 549 & $100 \%$ \\
\hline
\end{tabular}

O mastocitoma e carcinoma de células escamosas, além de serem os tumores cutâneos mais frequentes, atingiram também várias áreas anatômicas com maior percentagem no abdômen, membros, períneo, escroto, pescoço e cauda.

Poodle foi a raça com maior frequência de tumores cutâneos, sendo que carcinoma de células escamosas $(13,20 \%)$ foi o mais prevalente, seguido de carcinoma de células basais $(13,20 \%)$ e lipoma $(9,43 \%)$. Já a raça Boxer teve o mastocitoma $(41,17 \%)$, carcinoma de células escamosas $(17,64 \%)$ e histiocitoma $(7,84 \%)$. A raça Pit Bull teve como resultados os tumores hemangiossarcoma $(27,5 \%)$, carcinomas de células escamosas $(27,5 \%)$ e com $12,5 \%$ os tumores mastocitoma e hemangioma.

Dentre os casos de carcinoma de células escamosas, $57,64 \%$ dos cães $(n=49)$ possuíam toda a pele despigmentada ou parte dela e $42,35 \%$ ( $n=$ 36) apresentavam outra coloração de pele.

A probabilidade dos cães estudados apresentarem diferentes tipos de tumores foi avaliada e constatou-se que considerando os 
tumores carcinoma de células escamosas e mastocitoma não houve diferença na probabilidade de apresentar um ou outro (Odds Ratio 1,01 de $0,74<$ OR $<1,36$ com intervalo de confiança $95 \%$ e um $\mathrm{p}=0,93)$. Já quando avaliada a probabilidade de apresentar os tumores carcinoma de células escamosas e mastocitoma (os tumores mais frequentes) comparando-se com os demais tumores menos frequentes houve diferença extremamente significativa no risco de apresentar carcinoma de células escamosas e mastocitoma (Odds Ratio 2,02 de $1,40<\mathrm{OR}<2,93$ com intervalo de $95 \%$ e $\mathrm{p}=$ $0,0002)$.

\section{DISCUSSÃO}

Em relação à frequência de tumores cutâneos de acordo com o sexo dos cães, a ocorrência foi maior em machos $(51,79 \%)$ corroborando com os resultados encontrados por Souza et al. (2006) e Meirelles et al. (2010), e difere dos resultados obtidos por Silveira et al. (2006) e Spander et al. (2007) que relatam a predominância nas fêmeas caninas na casuística. Segundo Meirelles et al. (2010) a maior frequência em machos pode ser devido aos tumores de glândula perianal e pelo fato das glândulas serem andrógeno-dependentes. Porém calculando o risco não houve diferença estatística significativa entre os sexos.

Os tumores ocorreram com maior frequência em cães adultos e idosos, assim como nos levantamentos realizados por De Nardi et al. (2002), Silveira et al. (2006) e Meirelles et al. (2010). A maioria dos tumores acontece principalmente em cães adultos e idosos, é rara sua ocorrência em cães filhotes e jovens e o maior número de casos de tumores cutâneos pode estar correlacionado ao aumento da sobrevida desses cães (MORRISON, 1998).

Cães SRD foram os mais acometidos e dentre os de raça, houve predomínio das raças Poodle, Boxer e Pit Bull. A frequência de tumores nas raças Poodle e Boxer foram semelhantes à De Nardi et al. (2002), Silveira et al. (2006) e Spander et al. (2007), existindo predisposição genética dessas raças para certos neoplasias cutâneas (MEIRELLES et al., 2010). A raça Pit Bull geralmente não é citada em trabalhos de estudos epidemiológicos, e isso pode ser explicado devido a raça ter sido introduzida em meados da década de 80 no Brasil e há pouco tempo houve um reconhecimento e crescimento pelo país. A raça também pode ser indicador de prognóstico, animais da raça Boxer tendem a apresentar tumores mais bem diferenciados e aqueles da raça Shar-Pei tendem a desenvolver tumores pouco diferenciados (MEDLEAU; HNILICA, 2009). Boxer foi a raça mais acometida pela neoplasia $(40,47 \%)$ seguida de Pit Bull (12,5\%).

A maioria dos tumores apresentou comportamento maligno $(65,39 \%)$, assim como relatado por Silveira et al. (2006) que encontraram $81 \%$ tumores malignos e ao contrário do observado por Wilkinson e Harvey (1996) no qual relatam que aproximadamente $50 \%$ das neoplasias cutâneas são de natureza benigna. Já a origem das neoplasias foi semelhante a observada por Souza et al. (2006) e diferente de Silveira et al. (2006) e Meirelles et al. (2010) que encontraram tumores mesenquimais com maior frequência e, em seguida, os epiteliais. A origem celular de neoplasias epiteliais frequentemente envolve superfície de revestimento e anexos com uma grande variedade de tipos de células e de glândulas (sudoríparas, sebáceas, hepatóide, entre outras) e podendo explicar a maior ocorrência nesse local da pele.

Foram diagnosticados 35 tipos de tumores e entre os mais comuns estavam o carcinoma de células escamosas e mastocitoma, resultados semelhantes aos encontrados por De Nardi et al. (2002) e Meirelles et al. (2010). A frequência de melanoma e fibrossarcoma foi semelhante a observada por Spander et al. (2007). Segundo Silveira et al. (2006) os tumores de origem maligna de maior ocorrência são os carcinomas basocelulares, hemangiossarcomas e mastocitomas e os de origem benigna são tricoepiteliomas, hemangiomas e lipomas, coincidindo com o presente trabalho no que tange o mastocitoma e hemangiossarcoma, e entre os benignos hemangioma e lipoma.

Comparando os dois tumores mais frequentes (carcinoma de células escamosas e mastocitomas) não houve maior probabilidade dos cães desenvolverem um tipo de tumor em relação ao outro, porém quando comparados com os tumores menos frequentes há um maior risco dos cães desenvolverem carcinoma ou mastocitoma.

As áreas mais acometidas foram abdômen, face, membros, períneo, escroto, tórax, pescoço e cauda, mostrando semelhança com os resultados de Souza et al. (2006) havendo apenas discrepância entre os valores de percentagem da região escrotal e nos tumores multifocais, sendo no presente estudo maior a incidência de neoplasias no escroto e menor dos tumores multifocais.

Segundo Medleau e Hnilica (2009) as áreas do tronco, períneo e membro são frequentemente acometidas pelo mastocitoma e carcinoma de células escamosas. Já Souza et al. (2006) citam a 
região abdominal como a mais acometida por esses tumores. No presente estudo, mastocitoma e carcinoma de células escamosas atingiram várias áreas anatômicas com maior percentagem no abdômen, membros, períneo, escroto, pescoço e cauda, assim como os referidos autores.

A cabeça foi a segunda região mais acometida, com presença de diversos tipos de tumores, e segundo Medleau e Hnilica (2009) os tumores de glândulas sebáceas, fibroma, hemangioma, hemangiossarcoma, histiocitoma, melanoma e tumor venéreo transmissível (TVT) são neoplasias frequentemente encontradas na cabeça, sendo o carcinoma de células basais e o carcinoma de células escamosas os mais frequentes neste trabalho.

Os tumores no escroto (mastocitoma, carcinoma de células escamosas e hemangiossarcoma) foram exclusivamente malignos, semelhante aos dados de Souza et al. (2006).

O carcinoma de células escamosas é uma neoplasia maligna de ceratinócitos, ocorre mais frequentemente na pele não pigmentada, com poucos pêlos e prejudicada pelo sol, acomete mais frequentemente áreas de flanco e ventre (MEDLEAU; HNILICA, 2009). Esse tipo de tumor prevaleceu em várias áreas anatômicas neste estudo e 57,64\% dos cães eram de pele clara ou com áreas despigmentadas.

Os tumores de mastócitos podem ter origem na medula óssea ou tecido conjuntivo e localizar-se em qualquer tecido, mas segundo Fox (1998) representam de sete a $27 \%$ de todos os tumores de pele e de 11 a $27 \%$ das neoplasias malignas em cães.

Os tumores de mastócitos foram os mais frequentes depois do carcinoma de células escamosas e atingiram várias localidades anatômicas, com ocorrência predominante nas regiões do escroto, tórax e cauda. Segundo Medleu e Hnilica (2009) o local da neoplasia também é importante para o prognóstico, pois tumores nas regiões inguinal, perianal, e subungueal, focinho e cavidades bucal e nasal geralmente ocasionam metástase, enquanto as neoplasias apendiculares são melhores.

\section{CONCLUSÕES}

Os tumores cutâneos mais frequentes foram de origem epitelial e de comportamento maligno e as regiões do abdômen cabeça e membros as áreas mais comuns para formação de tumores.

Não existe diferença no risco de manifestar tumores cutâneos entre os sexos, porém considerando-se os tipos de tumores há maior probabilidade da população canina apresentar carcinoma de células escamosas e mastocitomas em detrimento dos outros tipos de tumores cutâneos.

As raças Poodle, Boxer, Pit Bull e Dashchund foram as mais acometidas por tumores cutâneos, assim como cães adultos e idosos.

\footnotetext{
ABSTRACT: We analyzed the archives of the Animal Pathology Laboratory of the Federal University of Uberlândia Veterinary Hospital from 2000 to 2010 with the aim of conducting an epidemiological study. Protocols for skin biopsies of dogs were selected and the following information was collected: morphological diagnosis, anatomical location, age, gender, and breed. Five hundred forty-nine skin tumors were diagnosed in 543 dogs, of which 281 were males and 247 were females. Adult and older dogs were the most affected, and mongrel dogs, Poodles, Boxers, Pit Bulls, and Dashchunds were the most frequent breeds. Malignant tumors were present in $65.39 \%$ dogs, and most tumors were derived from epithelial cells. Squamous cell carcinoma was the predominant neoplasia, followed by mast cell tumors and histiocytoma. With respect to the anatomic location, the abdomen (19.49\%), head (16.40\%), and limbs (15.30\%) were the most frequently affected. Gender did not influence the probability of having a cutaneous tumor. With regard to tumor type, the canine population was more susceptible to squamous and mast cell tumors than to other skin tumors.
}

KEYWORD: Mast cell tumor. Skin. Dogs. Squamous cell carcinoma. Tumors.

\section{REFERÊNCIAS}

DE NARDI, A. B.; RODASKI, S.; SOUSA, R. S.; COSTA, T. A.; MACEDO, T. R.; RODIGHERE, S. M.; RIOS, A.; PIEKARZ, C. H. Prevalência de neoplasias e modalidades de tratamento em cães atendidos no Hospital Veterinário da Universidade Federal do Paraná. Archives of Veterinary Science, Curitiba, v. 7, n. 2 , p. 15-26, 2002. 
FOX, L. E. Mast cell tumors. In: MORRISON, W.B. Cancer in Dogs and Cats: Medical and Surgical Management. Baltimore: Williams \& Wilkins, 1998. 477-486p.

GOLDSCHMIDT, M. H.; HENDRICK, M. J. Tumors of the skin and soft tissues. In: MEUTEN, D. J. (Ed.). Tumors in Domestic Animals. Iowa: Blackwell, 2002. p. 45-117. http://dx.doi.org/10.1002/9780470376928.ch2

GOORMAN, N.T.; DOBSON, J.M. The skin and associated tissues. In: WHITE, R.A.S. Manual of Small Animal Oncology. Shurdington: British Small Animal, 1995. p.187-200.

JONES, T. C; HUNT, R. D; KING, N. W. A pele e seus apêndices. In: Paulo: Manole, 1997. p. 831-884. . Patologia Veterinária. São

MEDLEAU, L.; HNILICA, K. A. Dermatologia de Pequenos Animais: Atlas colorido e guia terapêutico. 2 ed. São Paulo: Roca, 2009. 512 p.

MEIRELLES, A. E. W. B.; OLIVEIRA, E. C., RODRIGUES, B. A.; COSTA, G. R.; SONNE, L.; TESSER, E. S.; DRIEMEIER, D. Prevalência de neoplasmas cutâneos em cães da Região Metropolitana de Porto Alegre, RS: 1.017 casos (2002-2007). Pesquisa Veterinária Brasileira, Rio de Janeiro, v. 30, n. 11, p. 968-973, 2010.

MORRISON, W. B. Cancer in Dogs and Cats: Medical and Surgical Management. Baltimore: Williams \& Wilkins, 1998, 749p.

MURPHY, S. Skin neoplasia in small animals. Principles of diagnosis and management. In Practice, Londres, v. 28, n.6, p. 266-27, 2006.

SILVEIRA, L. M. G.; CUNHA, F. M.; MARZANO, T. F.; CALDERARO, F. F.; BONAMIN, L. V. Estudo crítico de neoplasias cutâneas em cães. Revista do Instituto de Ciências da Saúde, Campinas, v. 24, n. 6, p. 169-73, 2006.

SOUZA, T. M.; FIGHERA, R. A.; IRIOGOYEN, L. F.; BARROS, C. S. L. Estudo retrospectivo de 761 tumores cutâneos em cães. Ciência Rural, Santa Maria, v. 36, n. 2, p. 555-560, 2006.

http://dx.doi.org/10.1590/S0103-84782006000200030

SPANDER, M. B.; GUIM, T. N.; SILVEIRA, M. F.; GAMBA, C. O.; SCOPEL, D.; SCHUCH, I.; BONELRAPOSO, J.; FERNANDES, C. G. Estudo Retrospectivo de Neoplasmas Diagnosticados durante o período de 2002 a 2006. In: XVI Congresso de Iniciação Científica, 2007. Disponível em:

http://www.ufpel.tche.br/cic/2007/cd/pdf/CA/CA_00785.pdf. Acesso em: 10 fev.2011

WILKINSON, G. T., HARVEY, R. G. Atlas colorido de dermatologia de pequenos animais: guia para diagnóstico. 2 ed. Barueri: Manole, 1996. 304p.

WILLEMSE, T. Dermatologia clínica de cães e gatos. 2 ed. Barueri: Manole, 1998. 80p.

WILTHROW, S. J.; VAIL, D. M. Tumors of the skin and subcutaneous tissues. In: . Small Animal

Clinical Oncology. 4 ed. Philadelphia: Saunders, 2001. 375p. 